\title{
Investigations on the structure of ETFE-films and their influence on the design, a survey with recommendations for the analysis
}

\author{
Rainer Blum ${ }^{\dagger}$, Heidrun Bögner-Balz*, and Jochen Köhnlein* \\ * DEKRA Automobil GmbH \\ Laboratory for Technical Textiles and Films \\ Handwerkstr.17 * D 70565 Stuttgart \\ Tel.: +49.711.7861-4111* Fax: +49.711.7861-4115 \\ Email: heidrun.boegner-balz@dekra.com*Web page: http://www.dekra.com \\ ${ }^{\dagger}$ Formfinder \\ Email: r.blum@labor-blum.de \\ Web page: http://www.formfinder.at
}

\begin{abstract}
The structure of an ETFE film is semicrystalline, to be composed of a crystalline phase and an amorphous one. Both components show a different behaviour under mechanical loading. As a consequence, the behaviour under uniaxial loading differs from the one under biaxial loading. This will be shown by the results of respective experiments. From these experiments one can conclude that the structure of the mechanical behaviour is transverse isotropic: The behaviour in the direction of the thickness is different from the one in the plane of the film.

This difference between the behaviour in uniaxial and biaxial loading is shown very clearly in the experiments where the load is increased beyond the yield point. In the biaxial case the deformations are less than in the uniaxial one. The viscous parts of the deformations are different too. But in both cases the behaviour, once the yield point is passed and the load is reduced, is more or less elastic with some viscous influences. Based on these experiments one can establish design rules for ETFE-films beyond the yield-point. Furthermore the „compensation deformation“ can be determined from the results of biaxial tests. These deformations are nothing else than the irreversible part of the plastic deformations. It is to add that the analysis of the structural behaviour of ETFE-films does not need to include elastic-plastic material behaviour, the knowledge of the irreversible part of the plastic behaviour is sufficient.

It shall be remarked that one can only get these results in measuring not only the in-plane part of the deformations but the part normal to the plane, too. This fact makes the measurements more complex. On the basis of uniaxial and biaxial tests and their measurement results, the properties listed above will be presented and verified.
\end{abstract}

\section{REFERENCES}

[1] Blum, R., Bögner-Balz, H., Köhnlein, J., On the mechanical behaviour of ETFE-films: Elastic range, yielding conditions, break determined by different test methods and the influence of the results on the analysis of ETFE-structures, Tensinet-Symposium 2016

[2] Menges, G., Haberstroh, E., Michaelei, W., Schmachtenberg, E.:

Werkstoffkunde Kunststoffe, München, 2002

[3] Moritz, K., ETFE-Folie als Tragelement, Dissertation, München, 2007

[4] Schiemann, L., Tragverhalten von ETFE-Folien unter biaxialer Beanspruchung, Dissertation, München, 2009

[5] BLUM, R., BÖGNER H., KÖHNLEIN, J., Internal Report, Stuttgart 2004, unpublished 